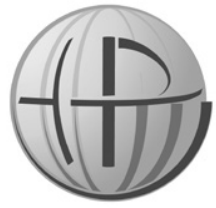

Horyzonty Polityki 2020, Vol. 11, No 37

\section{Justyna Domanowska}

http://orcid.org/0000-0002-6257-3475

Uniwersytet Łódzki

Wydział Zarządzania

justyna.domanowska@uni.lodz.pl

DOI: $10.35765 / H P .1958$

\title{
Strategiczna rola inteligencji wielorakich w procesie zarządzania wiedzą
}

\section{Streszczenie}

CEL NAUKOWY: Celem naukowym niniejszego artykułu jest przedstawienie rozkładu inteligencji wielorakich studentów pierwszego roku w dwóch grupach o profilach: analityka biznesu oraz logistyka.

PROBLEM I METODY BADAWCZE: Główny problem badawczy podjęty $\mathrm{w}$ niniejszej pracy dotyczył istnienia korelacji pomiędzy profilem inteligencji a profilem grupy oraz istnienia podobieństw wśród profili studentów pierwszego roku. Postawiono kilka pytań szczegółowych m.in. po to, by znaleźć uśredniony rozkład inteligencji, inteligencje dominujące, korelacje między poszczególnymi inteligencjami oraz ewentualne różnice pomiędzy grupami. Wstępem do realizacji badań były studia literatury przedmiotu. Metodą badawczą wykorzystaną do przeprowadzenia badań był kwestionariusz ankiety. Badania przeprowadzone były w warunkach pełnej dobrowolności i na zasadzie samooceny według pytań sugerowanych w jednej z pozycji literaturowych. Badaną grupa byli studenci pierwszego roku w liczbie 79 .

PROCES WYWODU: Istnieje wiele teorii na temat inteligencji, sposobów jej mierzenia oraz czynników ją determinujących. W niniejszym artykule, poza przedstawieniem głównych teorii, będzie opisana szerzej teoria inteligencji wielorakich Howarda Gardnera. Według niej istnieje nieznana liczba ludzkich zdolności, od inteligencji muzycznej zaczynając, a na inteligencji, która wymaga zrozumienia siebie kończąc. Każdą inteligencję uruchamia lub wyzwala pewien rodzaj dostarczonych z wewnątrz lub zewnątrz bodźców. Diagnoza 
jest podstawą skutecznego nauczania. Dla studentów świadomość rodzaju ich efektywnego stylu uczenia się jest bardzo ważna. Pozwala zidentyfikować mocne strony oraz oprzeć się na nich w procesie zdobywania wiedzy.

WYNIKI ANALIZY NAUKOWEJ: Analiza przeprowadzonych badań wykazała interesujące korelacje pomiędzy występującymi inteligencjami, a także podobieństwa pomiędzy profilami grup.

WNIOSKI, INNOWACJE, REKOMENDACJE: Badania mają charakter pilotażowy i powinny być pogłębione oraz rozszerzone w przyszłości. Zdaniem autora powinny wpłynąć na sposób zarządzania wiedzą zarówno przez prowadzących zajęcia, jak i samych studentów.

\section{SŁOWA KLUCZOWE:}

inteligencja, Howard Gardner, inteligencje wielorakie, optymalizacja procesu kształcenia, zarządzanie wiedzą

\section{Abstract}

\section{THE STRATEGIC ROLE OF MULTIPLE INTELLIGENCES IN THE MANAGEMENT OF KNOWLEDGE}

RESEARCH OBJECTIVE: The research objective of the article is to determine the distribution of multiple intelligences among first-year students.

THE RESEARCH PROBLEM AND METHODS: The main research problem undertaken in this paper concerned the existence of a correlation between the intelligence profile and the group profile. The existence of similarities among the intelligence profiles of first-year students. Several specific questions were posed in order to find the averaged intelligence distribution, dominant intelligences, correlations between individual intelligences, and possible differences between groups. The method used to conduct the research was a questionnaire. The research was carried out on a voluntary basis and on the basis of self-assessment according to questions suggested in one of the references.

THE PROCESS OF ARGUMENTATION: There are many theories about intelligence, ways of measuring, and factors determining it. In this article, apart from presenting the main theories, Howard Gardner's theory of multiple intelligences will be described in more detail. According to this theory, there is an unknown number of human abilities, from musical intelligence to the intelligence required to understand oneself. Each intelligence activates or triggers some kind of internal or external stimulus. It is important for students to be aware of the type of effective learning style they have. It allows to identify their strengths and use them in the process of knowledge acquisition. 
RESEARCH RESULTS: The analysis of the conducted research showed interesting correlations between the intelligences and similarities between the group profiles.

CONCLUSIONS, INNOVATIONS, AND RECOMMENDATIONS:

The studies are pilot studies and should be deepened and expanded in the future. According to the author, they should influence the way knowledge is managed.

\section{KeYWORDS:}

intelligence; Howard Gardner; multiple intelligences;

optimization of the education process; knowledge management

Inteligencja jest istotnym czynnikiem determinującym powodzenie i osiągnięcia życiowe człowieka, nic więc dziwnego, że zdolność ta stała się przedmiotem intensywnych dociekań psychologów (Strelau i Doliński, 2010).

Istnieje wiele teorii na temat inteligencji, sposobów jej mierzenia oraz czynników ją determinujących. W niniejszym artykule poza przedstawieniem głównych teorii, rozwinięta szerzej będzie teoria inteligencji wielorakich Howarda Gardnera. Inteligencja w tradycyjnym ujęciu jest rozumiana jako zdolność rozwiązywania zadań wchodzących w zakres testów inteligencji. Jest to wartość niewiele zmieniająca się $\mathrm{z}$ wiekiem $\mathrm{i}$ jest $\mathrm{w}$ niewielkim stopniu zależna od nauki i doświadczenia. Teoria Howarda Gardnera stoi w opozycji do jednolitego traktowania intelektu. Wymienia osiem różnych rodzajów uzdolnień oraz opowiada się za tym, że człowiek ma w sobie kombinację różnych rodzajów inteligencji. Wszyscy jesteśmy różni, głównie dlatego, że wszyscy mamy różne kombinacje inteligencji, które wymagają różnego podejścia celem zmaksymalizowania wyników.

Ludzie różnią się szybkością i jakością rozwiązywania problemów rodzinnych, szkolnych, zawodowych, sytuacyjnych itp. (Strelau i Doliński, 2010). Od lat 80. Teoria Inteligencji Wielorakich Gardnera wzbudza wiele pozytywnych emocji wśród nauczycieli. Wspierająca indywidualne podejście stała się punktem odniesienia dla wielu propozycji metodycznych na rynku edukacyjnym. 


\section{POJĘCIE INTELIGENCJI - PRZEGLĄD GŁÓWNYCH TEORII}

Pojęcie inteligencja (łac. intelligentia) jest łączone z nazwiskiem starożytnego filozofa rzymskiego Cycerona, który używał go w wystąpieniach dla określenia zdolności intelektualnych. Wielu badaczy zakłada, że na inteligencję składa się jeden lub więcej rodzajów zdolności umysłowych, zwanych czynnikami. Charles Spearman sformułował hipotezę, że u podłoża wszystkich zachowań uważanych za inteligentne istnieje pewien wspólny czynnik. Nazwał go czynnikiem "g" (Spencer, 2004). Uważał, że inteligencja człowieka stanowi ogólny i niezróżnicowany czynnik, który przejawia się we wszystkich zachowaniach ludzkich angażujących takie procesy umysłowe, jak rozumowanie i wnioskowanie.

Inteligencja to konstrukt teoretyczny odnoszący się do względnie stałych warunków wewnętrznych człowieka, determinujących efektywność działań, wymagających procesów poznawczych. Warunki te kształtują się w wyniku interakcji genotypu środowiska i własnej aktywności człowieka (Strelau, 1987).

Pierwsze testy inteligencji opublikowali w 1905 roku dwaj Francuzi, Alfred Binet i Theodore Simon (Boyd i Bee, 2007). Narzędzie, które stworzyli, miało badać pewną specyficzną własność umysłu, charakterystyczną dla każdej jednostki i tłumaczącą w pewien sposób osiąganie sukcesów w szkole i na innych polach. Miało to ułatwić wyłonienie tzw. „zdolnych jednostek”. Pomiar dokonywany za pomocą tego narzędzia pozwalał na bardzo jednostronną ocenę umiejętności logicznego myślenia oraz prawidłowego, płynnego wysławiania się. Prace Alfreda Bineta rozwinął William Stern, wprowadzając w 1912 roku pojęcie ilorazu inteligencji (Inteligence Quotient - IQ), rozumianego jako iloraz wieku umysłowego dziecka do wieku życia, pomnożonego przez 100. Definiował on inteligencję jako ogólną zdolność jednostki do radzenia sobie w nowych sytuacjach oraz umiejętność przystosowania się do zmieniających się okoliczności (Strelau i Doliński, 2010). Kolejną teorię na temat inteligencji przedstawił Louis Thurstone (1938). Sugerował on istnienie dziewięciu odrębnych czynników, które nazwał podstawowymi zdolnościami umysłowymi. Można uzyskać wysokie wyniki w jednym z czynników, co nie przekłada się na zdolność 
w rozwiązywaniu problemu z zakresu innego czynnika (Thurstone i Thurstone, 1963).

Tabela 1

Podstawowe zdolności umysłowe wedtug Thurstonea

\begin{tabular}{|l|l|}
\hline & \multicolumn{1}{|c|}{ Opis } \\
\hline Zdolności wizualne i przestrzenne & wyobrażanie form i relacji przestrzennych \\
\hline Szybkość percepcyjna & $\begin{array}{l}\text { szybkie dostrzeganie szczegółów, podobieństw } \\
\text { i różnic między bodźcami }\end{array}$ \\
\hline Zdolności liczbowe & wykonywanie operacji na liczbach \\
\hline Znaczenie werbalne & znajomość znaczenia słów \\
\hline Pamięć & przypominanie sobie informacji \\
\hline Płynność słowna & $\begin{array}{l}\text { szybkość posługiwania się słowami } \\
\text { (rymowanie, rozwiązywanie krzyżówek) }\end{array}$ \\
\hline Rozumowanie dedukcyjne & $\begin{array}{l}\text { wyprowadzanie przykładów z prawidłowości } \\
\text { ogólnych }\end{array}$ \\
\hline Rozumowanie indukcyjne & $\begin{array}{l}\text { wyprowadzanie prawidłowości ogólnych } \\
\text { z przykładów }\end{array}$ \\
\hline
\end{tabular}

Źródło: (Spencer, 2004, str. 411)

\section{HOWARD GARDNER I TEORIA INTELIGENCJI WIELORAKICH}

Howard Gardner jest amerykańskim psychologiem specjalizującym się w zakresie psychologii rozwojowej. W 1979 roku projekt „Natura i realizacja potencjału ludzkiego" zaowocował opublikowaniem w 1983 roku Frames of Mind: The Theory of Multiple Intelligences (Ramy umystu. Teoria inteligencji wielorakich). Pozycja ta zawierała syntetyczne ujęcie przemyśleń autora dotyczące przeprowadzonych badań dzieci i dorosłych z uszkodzeniami mózgu. Doszedł on do wniosku, że istnieje nieznana liczba ludzkich zdolności, od inteligencji muzycznej zaczynając, a na inteligencji, która wymaga zrozumienia siebie kończąc. Każdą inteligencję uruchamia lub wyzwala pewien rodzaj dostarczonych z wewnątrz lub zewnątrz informacji.

Teoria Howarda Gardnera podaje całą listę umiejętności i zdolności człowieka. Jest to przeciwieństwo teorii jednostronnego patrzenia na jednostkę. Zauważono, że uczniowie nie mają jednej inteligencji, ale zakres inteligencji, tzw. inteligencje wielorakie (Gardner, 1983). 
Nie wszyscy mają takie same zainteresowania i zdolności. Nie wszyscy uczą się w ten sam sposób. Nikt nie jest w stanie nauczyć się wszystkiego, czego można się nauczyć. Sprawą bardzo ważną wydaje się więc umiejętność rozpoznawania dominujących rodzajów inteligencji lub ich kombinacji. Teoria inteligencji wielorakich jest bardzo pomocna w edukacji. Zmusza do przemyślenia sposobu, w jaki powinno się podchodzić do przekazywania wiedzy, aby uczynić proces ten najefektywniejszym.

Pierwotnie wyróżniono siedem inteligencji, w późniejszym czasie dołączyła ósma - inteligencja przyrodnicza. Inteligencje wielorakie Howarda Gardnera to:

- Inteligencja językowa, czyli zainteresowanie światem słowa mówionego i pisanego. To umiejętność swobodnego korzystania ze słów oraz języka, umiejętność używania synonimów oraz sprawnego wypowiadania się i logicznego ujmowania zdarzeń, to wrażliwość na rymy, znaczenie słów.

- Inteligencja matematyczno-logiczna to świat symboli liczbowych, operacji matematycznych. Świat odbierany jest poprzez liczby oraz ciągi zdarzeń. To rodzaj inteligencji opartej na myśleniu przyczynowo-skutkowym oraz wykorzystującej logikę, algorytmy oraz schematy.

- Inteligencja muzyczna to wrażliwość na bodźce słuchowe, dźwięki, rytm, muzykalność oraz melodie; to otaczanie się muzyką i dźwiękami jako formą pojmowania świata.

- Inteligencja wizualno-przestrzenna to umiejętność tworzenia w umyśle obrazów, relacji przestrzennych oraz wizualizacji. Świat odbierany jest poprzez obraz i formy przestrzenne. To myślenie obrazami oraz duża wrażliwość na szczegóły i detale.

- Inteligencja ruchowa to zdolność wykorzystywania własnego ciała; świat odbieramy jest tu poprzez ruch i kontakt fizyczny. Komunikacja ze światem odbywa się często za pomocą gestykulacji oraz nierzadko wykorzystywany jest język ciała.

- Inteligencja interpersonalna, czyli łatwość wchodzenia w interakcje z innymi, umiejętność komunikowania się, negocjowania, wypracowywania kompromisów. To również wysoka potrzeba kontaktów międzyludzkich.

- Inteligencja intrapersonalna to wysoka samoświadomość, zdolność do refleksji nad sobą, własnym zachowaniem 
i postępowaniem, motywacją i emocjami. Wiąże się często z tzw. „mądrością życiową”, wysoką intuicją, wewnętrzną motywacją oraz silną wolą do działania.

- Inteligencja przyrodnicza - cechuje ją duża wrażliwość na świat fauny i flory, a świat odbierany jest poprzez naturalne środowisko i otoczenie. To inteligencja opierająca się na poznaniu, docenianiu i zrozumieniu natury. Odznacza się zdolnością rozumienia i czerpania wiedzy z obserwacji środowiska naturalnego.

Inteligencje, w czystej formie, spotkać można tylko u jednostek będących z technicznego punktu widzenia idiotami. U prawie wszystkich pozostałych osób różne rodzaje inteligencji współdziałają ze sobą w celu rozwiązywania problemów i tworzenia różnych ostatecznych stanów kulturowych (Strelau, 1987).

Teoria inteligencji wielorakich uznaje istnienie wielu różnych, niezwiązanych ze sobą aspektów poznania. Opierają się one na założeniu, że różni ludzie mają różne zdolności poznawcze i odmienne style poznawania, a inteligencja jest wynikającą z ludzkiej biologii i psychologii zdolnością przetwarzania pewnego rodzaju informacji.

\section{DIAGNOZA PEDAGOGICZNA I PRAKTYCZNE WYKORZYSTANIE TEORII GARDNERA}

W języku greckim „diagnoza” oznacza rozróżnienie, osądzanie. Diagnoza to zebranie $\mathrm{w}$ odpowiedni sposób danych, które wymagają interpretacji i oceny, a następnie określenie badanego złożonego stanu rzeczy.

Diagnoza jest podstawą skutecznego nauczania. Dla studentów świadomość rodzaju ich efektywnego stylu uczenia się jest bardzo ważna. Pozwala zidentyfikować ich mocne strony i oprzeć się na nich $\mathrm{w}$ procesie zdobywania wiedzy. Aylin Tekiner badała związek pomiędzy inteligencjami a percepcyjnymi i społecznymi stylami uczenia się studentów uniwersytetów tureckich. Stwierdzono, że istnieją pozytywne relacje między inteligencją logiczno-matematyczną i intrapersonalną a indywidualnym stylem uczenia się oraz inteligencją interpersonalną a grupowym stylem uczenia się (Tekiner, 
2005). W 2009 roku A. Saricaoglu i A. Arikan wykazali zależność pomiędzy płcią a inteligencją językową (Saricaoglu i Arican, 2009).

Teoria inteligencji wielorakich Howarda Gardnera to nowe spojrzenie na inteligencję. Jej założenie jest takie, że wszyscy ludzie mają inteligencje. W każdej osobie jedna z nich jest wyraźniejsza. Z pomocą tej teorii można lepiej zrozumieć indywidualne różnice, a także zrozumieć i poprawić środowisko nauczania oraz uczenia się.

Prowadzący zajęcia zgodnie z teorią Howarda Gardnera może dotrzeć do słuchaczy, wykorzystując następujące narzędzia:

- słowa - przy inteligencji językowej,

- liczby - przy inteligencji logiczno-matematycznej,

- obrazy - przy inteligencji przestrzennej,

- muzykę - przy inteligencji muzycznej,

- samorefleksję - przy inteligencji intrapersonalnej,

- ruch - przy inteligencji kinetycznej,

- doświadczenie grupowe - przy inteligencji intrapersonalnej,

- związek ze światem przyrodniczym - przy inteligencji przyrodniczej.

Ludzie różnią się szybkością i jakością rozwiązywania problemów zarówno życiowych, zawodowych, jak i sytuacyjnych (Strelau, 1987). Teoria Gardnera o inteligencjach wielorakich jest dobrze znana i ceniona na świecie. Ma znaczący wpływ na edukację w wielu krajach. Pozwala odkryć zainteresowania i podążać w kierunku umiejętności i zainteresowań jednostki, co znacząco usprawnia proces edukacyjny.

\section{METODOLOGIA I WYNIKI BADAŃ}

Badanie ma charakter pilotażowy i przeprowadzono je na wybranym przez autora teście, opisanym w literaturze (Kopik i Zatorska, 2010, s. 44-46). Studenci pierwszego roku wydziału zarządzania proszeni byli o zaznaczenie odpowiedzi na pytania. Kwestionariusz ankiety składał się z 48 pytań oraz pięciostopniowej skali odpowiedzi. Analizie poddano wyniki testów inteligencji dla $\mathrm{N}=79$ studentów. 
Rys. 1. Średnie wartości poszczególnych inteligencji dla studentów pierwszego roku

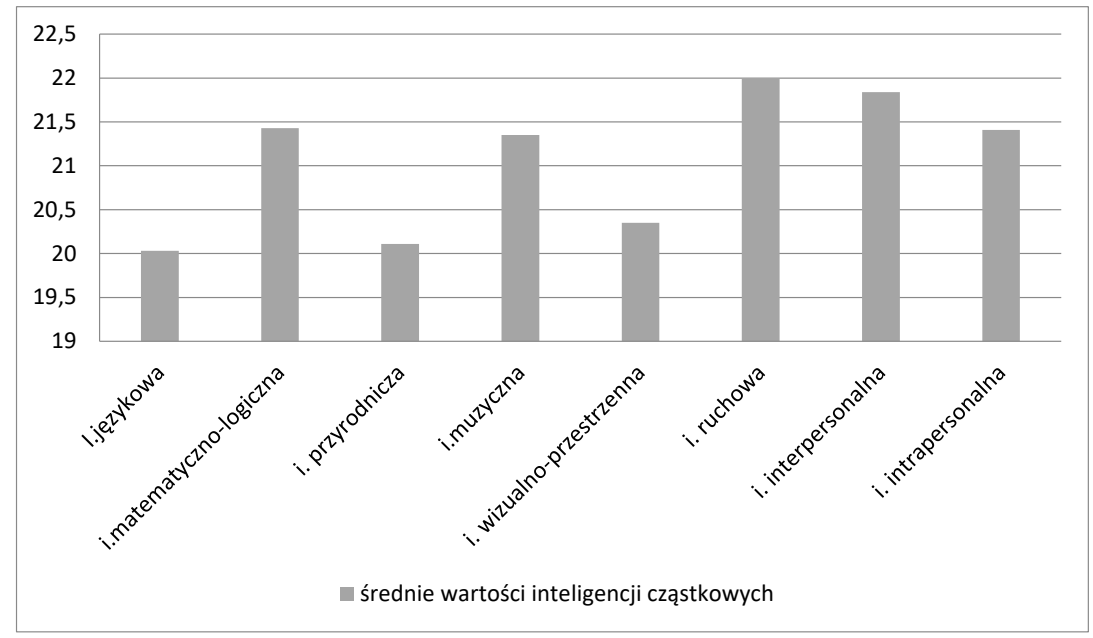

Źródło: opracowanie własne.

Najwyższy średni wynik studenci uzyskali w zakresie inteligencji ruchowej, co może wiązać się z wiekiem ankietowanych oraz nieustanną potrzebą ruchu. Najsłabsze wyniki osiągnięto dla inteligencji językowej, co, porównując z wysokim wynikiem inteligencji matematyczno-logicznej, może wskazywać na częściowe wykluczanie się tych inteligencji. Wysokie wyniki dla inteligencji matematyczno-logicznej wskazują na zgodność predyspozycji intelektualnych z wybranymi specjalizacjami: analityką i logistyka, gdzie umiejętność logicznego myślenia oraz myślenia przyczynowo-skutkowego jest niezwykle cenioną umiejętnością. Dominująca inteligencja interpersonalna wskazuje na potrzebę grupowej interakcji przy rozwiązywaniu problemów czy opracowywaniu wyników, a intrapersonalna na tzw. „mądrość życiową”, intuicję i wewnętrzną motywację badanych. 


\section{Justyna Domanowska}

Tabela 2

Statystyki opisowe wyników inteligencji

\begin{tabular}{|c|c|c|}
\hline Zmienna & Parametr & Ogółem $(\mathrm{N}=79)$ \\
\hline \multirow[t]{3}{*}{ Inteligencja językowa } & średnia (SD) & $20,03(3,2)$ \\
\hline & mediana (IQR) & $20(18-22)$ \\
\hline & zakres & $13-29$ \\
\hline \multirow[t]{3}{*}{ Inteligencja matematyczno-logiczna } & średnia (SD) & $21,43(2,9)$ \\
\hline & mediana (IQR) & $21(20-23)$ \\
\hline & zakres & $14-28$ \\
\hline \multirow[t]{3}{*}{ Inteligencja ruchowa } & średnia (SD) & $22(3,86)$ \\
\hline & mediana (IQR) & $22(20-25)$ \\
\hline & zakres & $13-29$ \\
\hline \multirow[t]{3}{*}{ Inteligencja wizualno-przestrzenna } & średnia (SD) & $20,35(3,58)$ \\
\hline & mediana (IQR) & $21(17-23)$ \\
\hline & zakres & $14-27$ \\
\hline \multirow[t]{3}{*}{ Inteligencja muzyczna } & średnia (SD) & $21,35(4,53)$ \\
\hline & mediana (IQR) & $22(18,5-24)$ \\
\hline & zakres & $12-30$ \\
\hline \multirow[t]{3}{*}{ Inteligencja przyrodnicza } & średnia (SD) & $20,11(4,31)$ \\
\hline & mediana (IQR) & $21(17-23)$ \\
\hline & zakres & $9-29$ \\
\hline \multirow[t]{3}{*}{ Inteligencja intrapersonalna } & średnia (SD) & $21,41(3,38)$ \\
\hline & mediana (IQR) & $22(20-23,5)$ \\
\hline & zakres & $10-29$ \\
\hline \multirow[t]{3}{*}{ Inteligencja interpersonalna } & średnia (SD) & $21,84(4,06)$ \\
\hline & mediana (IQR) & $22(19-25)$ \\
\hline & zakres & $11-30$ \\
\hline \multirow[t]{2}{*}{ Grupa } & $\mathrm{AB}$ & $48,1 \%(\mathrm{~N}=38)$ \\
\hline & LO & $51,9 \%(\mathrm{~N}=41)$ \\
\hline
\end{tabular}

Źródło: opracowanie własne.

Najmniejszy rozstęp międzykwartylowy osiągnięto dla inteligencji matematyczno-logicznej i intrapersonalnej, co wskazywałoby na większą jednorodność grupy pod względem tych dwóch cech. Są to inteligencje $z$ oczywistych powodów dominujące w pracy analityków oraz związane ściśle z logistyką która wymaga logicznego myślenia przyczynowo-skutkowego. Największy rozstęp międzykwartylowy 
wystąpił w wynikach inteligencji interpersonalnej, wizualno-przestrzennej, muzycznej i ruchowej, co może wskazywać, że inteligencje te nie są inteligencjami dominującymi w grupie, a są bardziej związane z pasjami, które ankietowani mają. Duże wartości IQR wiążą się z dużym zróżnicowaniem wyników dla różnych studentów.

Rys. 2. Wykres pudełkowy wyników inteligencji

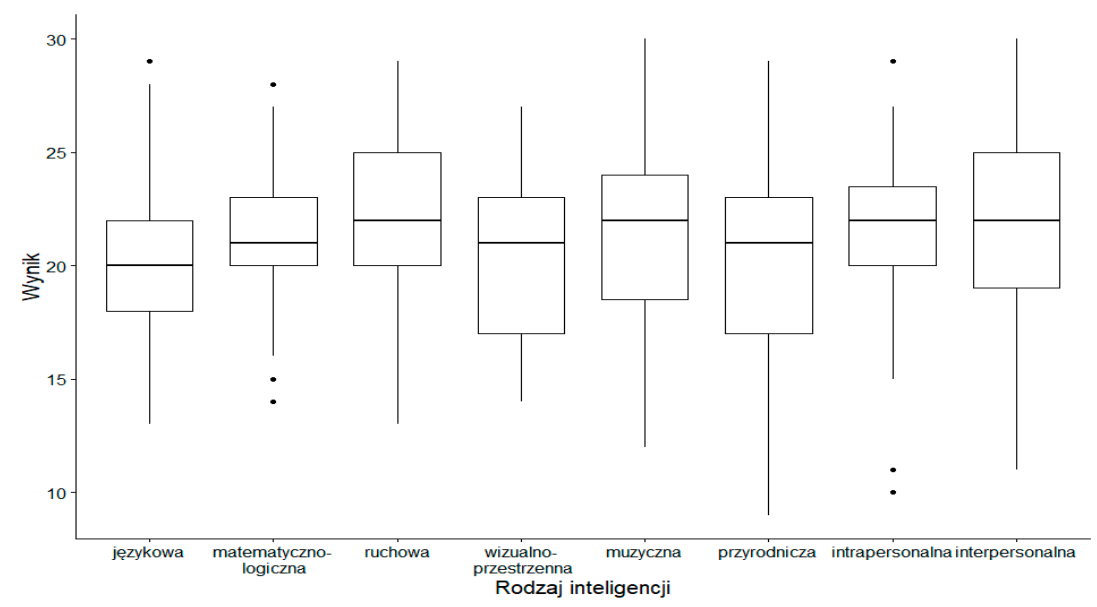

Źródło: opracowanie własne.

W celu porównania ze sobą rodzajów inteligencji poszczególnych grup wykonano test rang Kruskala-Wallisa. P - wartość mniejsza niż założony poziom istotności $(0,05)$ wskazuje na to, że istnieją istotne różnice pomiędzy wynikami dla grup.

Tabela 3

Wyniki testu Kruskala-Wallisa

\begin{tabular}{|c|c|c|c|}
\hline Test & Statystyka testowa & Liczba stopni swobody & P-wartość \\
\hline rang Kruskala-Wallisa & 25,57 & 7 & $<0,001$ \\
\hline
\end{tabular}

Źródło: opracowanie własne.

Studentów podzielono na pochodzących z grup AB oraz LO. Około 51,9\% studentów należało do grupy LO - logistyka, a reszta do grupy $\mathrm{AB}$ - analityka biznesu. Dla wszystkich rodzajów inteligencji wykonano testy Wilcoxona-Whitneya-Manna do porównania wyników między grupami. 
Istotne różnice pomiędzy grupami zaobserwowano w przypadku inteligencji przyrodniczej. Wyższymi wynikami mogą pochwalić się studenci z grupy logistyka w porównaniu do osób z grupy analityka biznesu, natomiast jeśli chodzi o wynik testu inteligencji interpersonalnej były one wyższe dla grupy analityka biznesu. Są to ciekawe spostrzeżenia, potwierdzające hipotezę dotyczącą pewnych cech wspólnych w obrębie danej grupy specjalizacyjnej oraz wymagają dalszych potwierdzeń $w$ kolejnych badaniach na większych grupach lub w innych środowiskach.

Rys. 3. Porównanie wyników testów inteligencji z podziałem na grupy studentów

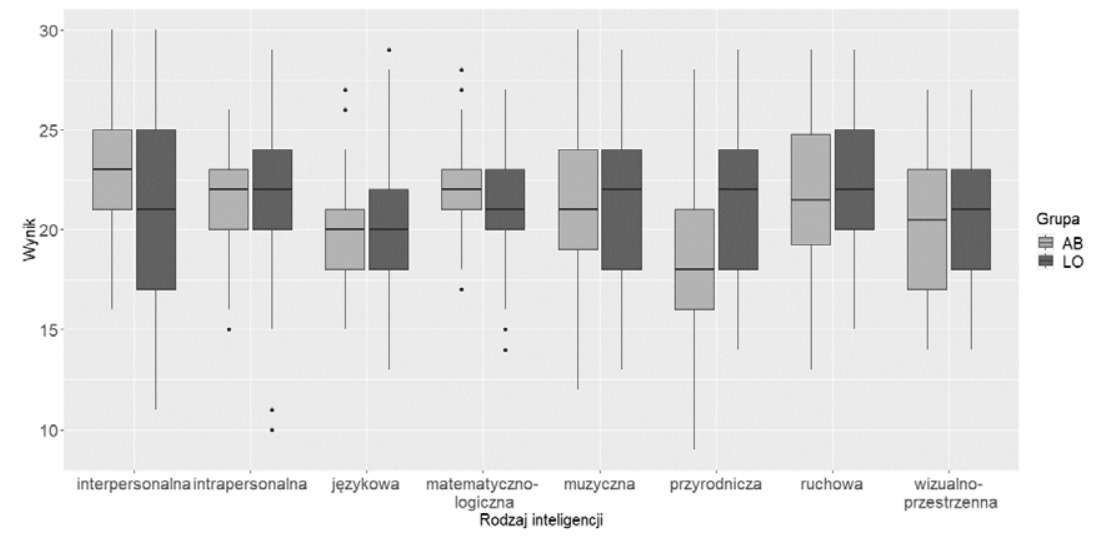

Źródło: opracowanie własne.

\section{PODSUMOWANIE}

„Każda teoria może pozwolić dotrzeć nam do jakiegoś zakątka rzeczywistości społecznej lub spojrzeć na dany zakątek z innej perspektywy" (Melosik, 1995). Przeprowadzone badania pozwoliły zapoznać studentów z teorią Gardnera. Zwróciły uwagę na pozytywne aspekty wiedzy o własnych możliwościach oraz silnych i słabych stronach. Nie był zaskoczeniem wysoki wskaźnik inteligencji matematyczno-logicznej, typowej dla przedstawicieli studiów wymagających dociekliwości i uporządkowania. Nie dziwi również wyższy poziom tego typu inteligencji w grupie analityka biznesu (AB), co wskazywałoby na zgodność profilowania z predyspozycjami. 
Zastanawiający jest niski wynik inteligencji językowej i może być podstawą do przemyśleń na temat częściowego wykluczania się tych typów inteligencji oraz wymaga dalszych pogłębionych badań. Dominująca inteligencja interpersonalna wskazuje na potrzebę grupowej interakcji przy rozwiązywaniu problemów czy opracowywaniu wyników, a w przyszłości pomaga w pracy zespołowej, która jest często podstawowym sposobem realizacji zadań. Znacznie wyższy poziom tej inteligencji w grupie $\mathrm{AB}$ wskazywałby na większą komunikatywność oraz nastawienie na współpracę wśród studentów na tym kierunku. Inteligencja intrapersonalna wskazuje na introwertyczność i mimo że występuje na podobnym poziomie w obydwu badanych grupach, to w grupie analityka biznesu ma mniejszy rozstęp międzykwartylowy, co wskazywałoby na większą jednorodność grupy pod względem tej cechy. Przynależność do pokolenia Y, które powszechnie i z łatwością korzysta z technologii informatycznych i komunikacyjnych, pogłębia dodatkowo cechy takiego zachowania.

Ciekawym spostrzeżeniem jest wysoki wskaźnik inteligencji przyrodniczej oraz istotne różnice pomiędzy grupami w tym przypadku. Wyższymi wynikami mogą pochwalić się studenci z grupy logistyka w porównaniu do osób z grupy analityka biznesu.

Inteligencja ogólna IQ kategoryzuje osoby na uczące się szybciej lub wolniej, niezależnie od trybu nauczania. Teoria wielu inteligencji stanowi platformę i wskazówki dla prowadzących zajęcia w zakresie korzystania ze zintegrowanych strategii i działań instruktażowych w celu zaspokojenia różnych potrzeb pod względem profili inteligencji, stylów uczenia się i preferencji uczenia się (Sulaiman, Abdurahman i Abdurahim, 2010).

Przeprowadzone badania mogą stanowić inspirację do przeprowadzenia podobnych badań w innych środowiskach lub na inną skalę. Świadomość różnych inteligencji i różnych strategii nauczania może zoptymalizować motywację do uczenia się i poprawić proces zarządzania wiedzą. Niezwykle ważne jest, abyśmy rozpoznawali i pielęgnowali różnorodne ludzkie inteligencje i wszystkie kombinacje inteligencji. 


\section{BibliografiA}

Boyd, D. i Bee, H. (2007). Psychologia rozwoju człowieka. Poznań: Zysk i s-ka.

Campbell, J. (1994). Past, space and self. Cambridge: The MIT Press, a Bradford Book.

Clauss, G. (1987). Psychologia różnic indywidualnych w uczeniu się. Warszawa: WSiP

Gardner, H. (1983). Frames of Mind: The Theory of Multiple Intelligences. New York.

Gardner, H. (2001). Inteligencja. Wielorakie perspektywy. Warszawa: WSiP.

Gunst, G. (2004). A study of multiple intelligences among teachers in Catholic elementary schoools in the Archdiocese od Detroit.

Hoerr, T.R. (2000). Becoming a multiple intelligences school. Alexandria: VA: ASCD.

Kopik, A. i Zatorska, M. (2010). Wielorakie podróże - edukacja dla dziecka. Kielce: Europejska Agencja Rozwoju Sp.J.

Lubinski, D. (2004). Introduction to the special section on cognitive abilities: 100 years after Spearman's (1904) “General Intelligence,' objectively determined and measured." Journal of Personality and Social Psychology, 86, 96-111.

Melosik, Z. (1995 ). Postmodernistyczne kontrowersje wokół edukacji. Toruń-Poznań: Wyd. EDYTOR.

Saricaoglu, A. i Arican, A. (2009). A study of multipleintelligences, foreign language success and some selected variables. International Journal of Educational Researchers, 1(1), 22-36.

Spencer, A.R. (2004). Psychologia wspótczesna. Lepiej, więcej, przystępniej. Gdańsk: Gdańskie Wydawnictwo Psychologiczne.

Strelau, J. (1987). O inteligencji człowieka. Warszawa: Wiedza Powszechna.

Strelau, J. i Doliński, D. (2010). Psychologia akademicka. Podrecznik. Gdańsk: Gdańskie Wydawnictwo Psychologiczne.

Sulaiman, T., Abdurahman, A. i Abdurahim, S. (2010). Teaching strategies based on multiple intelligences theory among science and mathematics secondary school teachers. Procedia-Social and Behavioral Sciences, $8,512-518$.

Tekiner, A. (2005). The relationship between perceptional and social learning styles and multiple inteligences and their effectson English proficiency of Turkish young Adults learning English as foreign language. Ankara: The Middle East Technical University.

Thurstone, L. i Thurstone, T. (1963). SRA primary abilities. Chicago: SRA. 
Yalmanci, S. i Gozum, A. (2013). The effects of multiple intelligence theory based teaching on students. International Journal on New Trends in Education and Their Implications, 4(3), 27-36.

\section{Copyright and License}

This article is published under the terms of the Creative Commons Attribution - NoDerivs (CC BY- ND 4.0) License http://creativecommons.org/licenses/by-nd/4.0/ 